\title{
Educational Massively Multiplayer Online Role Playing Game For Teaching Youth Finance
}

\author{
David A. Jones and Maiga Chang \\ School of Computing and Information Systems, Athabasca University, Canada \\ djones@rrc.mb.ca and maiga@ms2.hinet.net
}

\begin{abstract}
It has been stated that people need to improve their knowledge of finances and make better choices with their money. Many programs have been created to teach basic finances. These programs target people of all ages from adults all the way down to kindergarten students. The vast majority of opinions on teaching finances state that education begins with children - the younger the better. The goal of this research project is to create a fun to play (massively) multiplayer online role playing game (MMORPG) capable of teaching younger students how to better manage their personal finances. The game is designed as an educational tool with an attempt to balance both the entertainment and educational components. It simulates a real world where the player must make financial decisions for their character in an attempt to develop enough wealth to allow that character to retire at a specified age.
\end{abstract}

Keywords-Massively Multiplayer Online Role Playing Game, MMORPG, Children, Finance, Money, Teach

\section{INTRODUCTION}

Thirty years ago all a person needed to know was how to balance a checking account and maintain a savings account. Today there are many more financial services, products and providers a person must be familiar with. When a person lacks the appropriate financial knowledge they are susceptible to making poor choices in selecting products and services. If properly educated the same person may make better financial decisions.

The vast majority of opinions on teaching finances state that education begins with children - the younger the better [1][12]. A child is much more willing and able to learn new concepts. In addition, a person's financial affairs have as much in common with attitudes and behaviors as they do with practical skills [10]. Starting to teach children early instills the proper attitudes and behavior which will allow them to be successful later in life. When these children become adults they are better able to handle money effectively [1] and have better financial habits [12] so they are more likely to be financially successful.

Creating a game where the player is in control of their character's financial future may be able to teach basic and advanced financial skills. The players will be able to try different financial tactics and see their results. These financial decisions will include most of the decisions that need to be made by today's adults living in the real world.

This paper is organized as follows: Section II will discuss the research and evaluation done on how financial concepts are taught. It will also look at why using a MMORPG would be a good approach for teaching finances. Section III will discuss how the game is to be designed, financial topics included and a description of how the game would be played. Section IV will focus on how the game is implemented. Section V will outline the evaluation of the game. Section VI will provide recommendations for further work and improvements to the game.

\section{RESEARCH BACKGROUND}

Several studies prove that a lack of financial literacy contributes to poor financial decisions. In one study that included questions on personal finance and economics, adults only obtained an average of $\mathrm{C}$ while students fared much worse with a mark of F [5]. Much of the problem is knowledge perception - many believe they are making wise decisions. In a 2003 study, $80 \%$ of the participants had confidence in the financial decisions they made, however only $42 \%$ of the participants answered financial questions correctly [5].

A major contributor to the problem is determining the best time to deliver the programs. Adults can be difficult to reach [11]. College students are typically not targeted since not everyone attends or takes financial courses [7]. The majority of programs currently seem to be targeted at high school students; however the effectiveness of these high school programs must be questioned. Many high school students who have taken financial education are no more financially literate than those that did not participate in these programs [7][8].

A successful study occurred in Chicago in 2005-2006. In this study, grade 6-8 students watched a play on financial matters then answered a series of questions based on the play. While all students showed improvement, the students in grade 6 improved the most [6]. Students in this grade are highly motivated to learn financial literacy. They have the skills necessary to learn the material and have generally not started making large financial decisions, so it is early enough in their life they can use the education to enhance their financial future.

A digital game may be an ideal approach to teach financial concepts. In a study released in 2010, an experiment to teach math using a digital game was done. Two groups of students participated. One group used the game to learn the math concepts while another used traditional techniques. In district testing both groups showed improvement in math skills with the game playing group showing significant improvement over the traditionally taught students [4]. Commercial games can also be used to 
teach. Age of Empires is used to teach Social Science and mathematics [3] while Civilization 3 was used to teach history [9]. Whether games are designed specifically for education or not they may offer educational opportunities.

\section{GAME DESIGN}

The game was developed as an educational tool with an attempt to balance both the entertainment and educational components. It is similar to a game in that it was developed in an artificially constructed world. It also contains simulation components as it tries to simulate the real financial situations a student will eventually find themselves in. Like both a game and a simulation there are rules and constraints that must be followed, plus there is a goal to be reached to 'win' the game. Concepts to be taught include the following:

- The importance of a higher education and its effect on earning potential;

- Getting a job and paying taxes;

- The costs associated with living including rent, utilities, food, clothing, transportation;

- Obtaining and handling credit (loans, mortgages, credit cards) properly;

- Protecting possessions with insurance;

- Saving for big purchases (house, furniture) and for retirement.

The game is designed to be used as a learning tool in an elementary school program. Teachers enroll the students to enable them to play the game. Once enrolled the student signs on and takes control of their game character. Student's characters start the game as young adults with the same possessions - the clothes on their backs and $\$ 1,000$.

Their first task is to locate a place to live. There are apartments to rent and houses to buy. Apartments are cheaper, therefore more affordable. Houses can be purchased, but require the player to obtain a mortgage. In order to get a mortgage the player must have a job.

There are several jobs available to the players from basic labour up to professional careers. Basic jobs are available to any player. Professional careers require advanced education - trade school, a diploma, bachelor, masters or PHD. These degrees are available from one of the educational institutions in the game. A player can also receive promotions based on job experience. These jobs are available at the company they work for, but require a certain level of experience.

Obtaining an education requires making financial decisions. Most players will not be able to pay cash for their education; they will need to obtain a student loan. While going to school the payments must be made, but they may not be working. They may need to make the decision to work part time (they will not be able to work full time and go to school).

Characters must make other financial decisions as well. These decisions include paying for daily living expenses (food, clothing) and utility bills. Characters will also need to purchase furniture for their living quarters, etc. Since players cannot purchase items they do not have money for, they can arrange to borrow funds from a bank or credit agency.
Depending on the bank or credit agency used, different interest rates will be charged. Using this credit wisely will allow the character to prosper financially.

Players will also be able and expected to interact with other players in the game. Students will be able to work together, assisting each other when necessary by providing financial advice, loaning of funds, etc.

Upon reaching retirement age the items and money saved by the player will be checked. The player must have the equivalent of $\$ 200,000$. This represents the amount necessary for their player to live 30 years in the retirement home.

If they have enough to retire the player 'wins' and the player's character will enter the Pecunia retirement home. If they do not have enough to retire, the player's character will be sent to the Pecunia employment office. In both cases this terminates the game for the player.

\section{SYSTEM ARCHITECTURE}

The system was developed using a tiered approach, using existing $3 \mathrm{D}$ software. There are two main tiers in the game, a tier running on a server and a tier running on a client.

The server tier runs the software 'Opensim'. This software is used to create virtual worlds similar to 'Second Life'. While the environment provided by Opensim and Second Life are nearly identical, Opensim was chosen. The current set-up for Second Life uses 'real' money. Players wanting to purchase items in the virtual world must purchase in-world currency using real money. In addition, many of the financial transactions to be implemented in the game (borrowing, renting, and credit) are not supported by Second Life. These transactions required changes to the back-end database, which are not possible in Second Life.

In addition to the 3D software used by the server, a web site was designed. This web site is used by the teachers to register students and by the students to enable their game character.

The client portion of the system uses modified version of the Hippo Opensim Viewer. The viewer was modified to remove some interface options that are too complex for the target audience or would allow them to circumvent game rules.

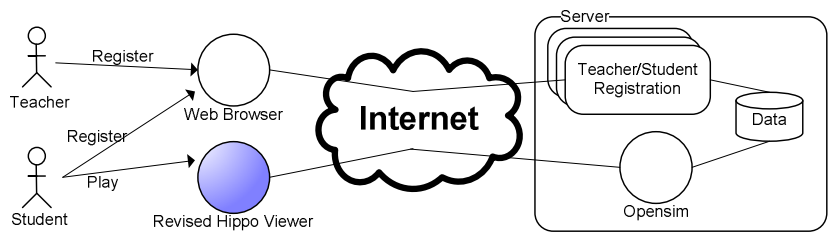

Figure 1. System architecture.

The 3D server software is designed to run on Microsoft Windows Server 2003 software only. While the OpenSim server software does run on multiple operating systems $(\mathrm{O} / \mathrm{S})$, only the Server $2003 \mathrm{O} / \mathrm{S}$ was developed.

The server uses the Apache HTTP Web Server, PHP for server side scripting and a MySQL database engine. The advantage to using these products is they are all open-source and free. 
The new viewer client was designed to run on Microsoft Windows XP only. While the software might work on other Windows versions it will not be guaranteed.

For testing purposes the developed 3D server software is on a stand-alone server. The client (the new viewer) is packaged as a distributable that can be installed on a Windows XP computer. Testing can be done from any client directly to the $3 \mathrm{D}$ server.

\section{Evaluation Plan}

Evaluation of the game will be done using a small group experiment. This will determine if the game is fun to play and educational. The approach being developed is to test knowledge on the game subject matter before game exposure (pretest), then test on the same subject matter after playing (posttest) [2][13]. In addition to the posttest, the small group will be given a usability questionnaire to determine how the game plays and whether it is fun.

\section{FUTURE WORK}

The game is a new approach to teaching finances. As a result, there are not a lot of other games to compare to. Possible ways to improve the game could include doing more research to ensure all financial topics are covered. In subsequent game releases more research may need to be done into what financial items are considered more important than others. In the first release all financial concepts are treated equally. This is likely not the case, so more research into identifying the most important concepts should be done.

The planned game flow depends heavily on user choice. It is possible that a player could go through the game without ever experiencing a particular financial event (getting a credit card for example). Subsequent releases should have some process in place that requires certain financial choices to be made without taking the control away from the player.

The game's financial world is based on stability and lacks inflation and recession factors. Introducing these factors would help students better understand how their financial decisions are affected by forces outside their control.

The pretest and posttest used to measure learning by the teacher are based on North American financial standards. These standards may not apply in other regions of the world. Giving the teacher the opportunity to revise these tests for their classes may improve their students learning experience.

\section{ACKNOWLEDGMENT}

The authors wish to thank the support of Athabasca University and the Mission Critical Research funding. Additional acknowledgements go out to the Opensimulator community. This community provides assistance and support to a multitude of users using the Opensim software. The developers of the Hippo Opensim viewer also require acknowledgement. This software has been developed to assist Opensimulator users by adding extra functionality not available in other viewers.

\section{REFERENCES}

[1] Alt Powell, E. (2004, Apr 11). Parents can teach children about personal finance. The Item, pp 1D, 2D. Retrieved August 13, 2010, from

http://news.google.com/newspapers?nid $=1980 \&$ dat $=20040410 \& i d=T$ 3MyAAAAIBAJ\&sjid=G68FAAAAIBAJ\&pg=2450,1540702

[2] Danes, S., Huddleston-Casas, C., \& Boyce, L. (1999). Financial Planning Curriculum For Teens: Impact Evaluation. Journal of Financial Counseling and Planning, 10(1), 26-39.

[3] Gros, B., \& Garrido, J. (2008). The Use of Videogames to Mediate Curricular Learning. In the Proceedings of the Second IEEE International Conference on Digital Games and Intelligent Toys Based Education, Banff, Alberta, Canada, November 17-19, 2008, 170-176.

[4] Kebritchi, M., Hirumi, A., \& Bai, H. (2010). The effects of modern mathematics computer games on mathematics achievement and class motivation. Computers \& Education, 55(2), 427-443.

[5] Lusardi, A., \& Mitchell, O. (2007). Financial literacy and retirement preparedness: evidence and implications for financial education; The problems are serious, and remedies are not simple. Business Economics, 42(1) 35-44. Retrieved August 13, 2010, from http://www.wiserwomen.org/pdf_files/research/2007_research.pdf

[6] Mandell, L. (2006). Teaching young dogs old tricks: The effectiveness of financial literacy intervention in pre-high school grades. In the Proceedings of the Academy of Financial Services Annual Conference, Salt Lake City, UT, USA, October 11, 2006. Retrieved August 13, 2010, from http://citeseerx.ist.psu.edu/viewdoc/download?doi=10.1.1.128.2740\& $\underline{\text { rep}}=$ rep1\&type $=$ pdf

[7] Mandell, L. (2009). The Impact of Financial Education in High School and College on Financial Literacy and Subsequent Financial Decision Making. In the Proceedings of the 2009 American Economic Association Conference, San Francisco, CA, USA, January 3-5, 2009. Retrieved August 13, 2010, from http://www.aeaweb.org/annual_mtg_papers/2009/retrieve.php?pdfid= $\underline{507}$

[8] Mandell, L., \& Klein, L.S. (2009). The impact of Financial Literacy Education on Subsequent Financial Behavior. Journal of Financial Counseling and Planning, 20(1), 15-24. Retrieved August 13, 2010, from

http://6aa7f5c4a9901a3e1a1682793cd11f5a6b732d29. gripelements.c om/pdf/lewis_mandell_linda_schmid_klein.pdf

[9] Martin, V. (2008). Online Videogames in an Online History Class. In the Proceedings of the Second IEEE International Conference on Digital Games and Intelligent Toys Based Education, Banff, Alberta, Canada, November 17-19, 2008, 146-148.

[10] Personal Finance Education Group. (2009). Teaching children about finance. Education Business, 14(6), 52. Retrieved August 13, 2010, from http://issuu.com/karlosullivan/docs/eb14.6

[11] Toussaint-Comeau, M., \& Rhine, S. (2002). Delivery of Financial Literacy Programs. Journal of Consumer Education, 19/20, 9-17. Retrieved August 13, 2010, from http://www.cefe.illinois.edu/JCE/archives/2001_2002_vol_19_20/Co meau\%20Rhine\%2020012002.pdf

[12] Truong, A. (2010, Apr 27). Don't wait to teach kids about finance. The Seattle Times. Retrieved August 13, 2010, from http://seattletimes.nwsource.com/html/living/2011714108_dollarteach 27.html?syndication $=$ rss

[13] Wilson, K. A., Bedwell, W. L., Lazzara, E. H., Salas, E., Burke, C. S., Estock, J. L., Orvis, K. L., \& Conkey, C. (2009). Relationships Between Game Attributes and Learning Outcomes: Review and Research Proposals. Simulation \& Gaming. 40(2), 217-266. 